\title{
The Relation of Left Ventricular Diastolic Dysfunction and Increased Left Ventricular Mass with Blood Pressure Variability in Non-Established Hypertensive Patients
}

Mohsen Ali Mahmoud Salama ${ }^{1}$, Yasser El Sayed Mohammed Hasan ${ }^{1}$, Moataz Abd Al Rahman Abd Al Salam Farag $2 *$

${ }^{1}$ Department of Cardiology, Faculty of Medicine, Al-Azhar University, ${ }^{2}$ Department of Cardiology, Matrouh Specialized Cardiothoracic and Interventional Catheterization Center, Egypt

*Corresponding author: Moataz Abd Al Rahman Abd Al Salam Farag, Mobile: (+20)01007859945, E-mail: muataz.7farag@ gmail.com

\section{ABSTRACT}

Background: long term high blood pressure is a major risk factor for coronary artery disease, stroke, heart failure, peripheral vascular disease, vision loss and chronic kidney disease.Objective: the aim of this study is to demonstrate the relation between left ventricular diastolic dysfunction, increased left ventricular mass and ambulatory blood pressure recording in subjects not known to be hypertensive.

Patients and Methods: this study is cross sectional study that was carried out on (100) normotensive patients in Cardiology Department Clinic at Matrouh Specialized Cardiothoracic and Interventional Catheterization Center from October, 2017 to January 2019. Results: significantly marked difference in left ventricular (LV) mass between two groups (normal blood pressure and latent hypertension) and significantly marked difference in diastolic dysfunction. According to (normal circadian and impaired circadian) there is significant difference between the two major groups in sex where male >female and marked difference in LV mass between the two groups (normal circadian and impaired circadian) and in smoking.

Conclusion: ambulatory blood pressure (AMBP) plays an important role as a predictor to estimate prevalence of hypertension based on diastolic dysfunction and increased left ventricular mass in persons with normal blood pressure measures at office specially masked hypertension in white coat hypertensive patients.

Keywords: Left ventricular diastolic, Blood pressure variability.

\section{INTRODUCTION}

Hypertension determines an increased risk of cardiovascular events which may be predicted by the occurrence of target-organ damage (TOD) ${ }^{(1)}$. In addition to elevated mean levels of blood pressure (BP), short-term daytime or 24-h BP variability (BPV) was shown to carry an independent prognostic value in hypertensive patients and is directly related to TOD ${ }^{(2)}$. Moreover, whenever present, left ventricular dysfunction in hypertension, even if asymptomatic, is a potent predictor of adverse cardiovascular events ${ }^{(\mathbf{3})}$.

With the growing acknowledgement of the importance of BPV, in its different components, as a possible new cardiovascular risk factor in hypertensive patients, BPV hypothesized its role in predicting subclinical left ventricular systolic dysfunction in newly diagnosed, never treated hypertensive patients, by focusing in our study on short-term BP variations occurring over a 24 -h period or selectively only during the daytime subperiod ${ }^{(4)}$.

Ambulatory BP becomes important tools for diagnosis of hypertension in pre hypertensive stage and white-coat or isolated clinic hypertension, which currently defines individuals whose blood pressure (BP) is elevated in the medical setting, but normal when assessed away from the medical environment, such as by 24-h ambulatory BP recording and/or home BP measurement ${ }^{(5)}$.

High normal blood pressure is defined as systolic blood pressure (SBP) $140 \mathrm{~mm} \mathrm{Hg}$ or higher and/or diastolic blood pressure (DBP) $90 \mathrm{~mm} \mathrm{Hg}$ or higher ${ }^{(6)} .3$

\section{AIM OF THE WORK}

The aim of this study is to demonstrate the relation between left ventricular diastolic dysfunction, increased left ventricular mass and ambulatory blood pressure recording in subjects not known to be hypertensive.

\section{PATIENTS AND METHODS}

This study is cross sectional study that was carried out on (100) normotensive patients in Cardiology Department Clinic at Matrouh Specialized Cardiothoracic and Interventional Catheterization Center from October, 2017 to January 2019.

The ethics committee of Al AZHAR University of Medical Sciences approved the study, and written informed consent was obtained from each patient after thorough explanation of the study to patients before enrollment.

\section{Inclusion criteria}

1. Age: $\geq 18$ years.

2. Sex: both sexes.

3. High normal blood pressure and left ventricular diastolic dysfunction and increased left ventricular mass according to hypertension guidelines.

\section{Exclusion criterions were:}

1. Any patient with blood pressure $>140 / 90 \mathrm{~mm} \mathrm{Hg}$.

2. Patients on current antihypertensive medication.

Patients with diabetes. 
The Relation of Left Ventricular Diastolic Dysfunction...

4. Renal dysfunction (serum creatinine $\geq 2 \mathrm{mg} / \mathrm{dl}$ or macro albuminuria $\geq 300 \mathrm{mg} / 24 \mathrm{~h}$ ).

5. Significant valvular or pericardial disease.

6. Heart failure.

7. Coronary heart disease.

8. Previous stroke.

9. Rhythm disturbances interfere with assessment of echocardiographic finding (e.g. right or left bundlebranch block and atrial fibrillation)

10. Patients with night-time working habits.

11. Patients with already depressed left ventricular ejectionfraction (LVEF) $(<55 \%)$.

\section{Each included patient was subjected to}

1. Full history taking about the presence of traditional risk factors, including a family history of hypertension, tobacco smoking, coffee or alcohol consumption, and lack of physical activity (defined as aerobic exercise on a regular basis three to four times per week). Thorough clinical examination: general and systematic examination.

2. Routine 12 leads ECG to diagnose any arrhythmia, IHD and evidence of chamber enlargement.

3. Chest $X$ ray: to exclude cardiomegaly

4. Routine laboratory tests.

5. Echocardiography with assessment according to recommendations of the American Society of echocardiography (ASE) to measure:

- Left ventricular internal dimensions

- Left ventricular mass

- Left ventricular ejection fraction by twodimensional echocardiography.

- Diastolic function indices include: E/A, Em, E/Em, LA volume, pulmonary artery pressure estimated by measurement of peak velocity of TR.

6. Twenty-four-hour ambulatory BP monitoring (ABPM).

7. AMBPM parameters : provides a more reliable measure of a patient's BP than isolated clinic measures and is not subject to the 'white-coat effect' which can overestimate BP, particularly in susceptible patients.

\section{All patients' had conventional office blood pressure measurement:}

All patients were seated comfortably in a quiet environment for $5 \mathrm{~min}$ before beginning $\mathrm{BP}$ measurements, three BP measurements should be recorded, 1-2 min apart, and additional measurements only if the first two readings differ by $>10 \mathrm{mmHg}$. BP is recorded as the average of the last two BP readings, with using a standard bladder cuff $(12-13 \mathrm{~cm}$ wide and $35 \mathrm{~cm}$ long) for most patients, but have larger and smaller cuffs available for larger (arm circumference $>32 \mathrm{~cm}$ ) and thinner arms, respectively, and the cuff was positioned at the level of the heart, with the back and arm supported to avoid muscle contraction and isometric exercise-dependent increases in $\mathrm{BP}$, with using phase I and V (sudden reduction/disappearance)
Korotkoff sounds to identify SBP and DBP respectively.

Measuring BP in both arms at the first visit to detect possible between-arm differences.

Patients underwent a $24 \mathrm{~h} \mathrm{ABPM}$ and a transthoracic echocardiogram. Based on the ABPMs (TONOPORT V, GE Medical Systems) a portable blood pressure measuring device, we analyzed average $24 \mathrm{~h}$ systolic and diastolic blood pressure (BP), average daytime (6 a.m.-10 p.m.) and nighttime (10 p.m.-6 a.m.) systolic and diastolic BP and the number of dipper or non-dipper patients according to the recommendations of ESC guidelines.

Transthoracic echocardiography was done using a commercially available echocardiographic instrument (Vivid S5, Vivid S6, GE Medical Systems) according to the recommendations of the American Society of echocardiography.

\section{Statistical analysis}

Recorded data were analyzed using the statistical package for social sciences, version 20.0 (SPSS Inc., Chicago, Illinois, USA). Quantitative data were expressed as mean \pm standard deviation (SD). Qualitative data were expressed as frequency and percentage.

\section{The following tests were done:}

- Independent-samples t-test of significance was used when comparing between two means.

- Chi-square $\left(\mathrm{x}^{2}\right)$ test of significance was used in order to compare proportions between two qualitative parameters.

- The confidence interval was set to $95 \%$ and the margin of error accepted was set to $5 \%$. The pvalue was considered significant as the following:

- Probability (P-value)

- P-value $<0.05$ was considered significant.

- P-value <0.001 was considered as highly significant.

- P-value >0.05 was considered insignificant.

\section{RESULTS}

We enrolled a consecutive subset of 100 patients. See tables 1-3 for their demographic, heart rate, and blood pressure data.

Table (1): Distribution of the studied cases according to demographics data $(n=100)$

\begin{tabular}{|c|c|c|c|}
\hline & & No. & $\%$ \\
\hline \multirow{3}{*}{ Gender } & Male & 66 & 66 \\
\cline { 2 - 4 } Age (years) & Female & 34 & 34 \\
\cline { 2 - 4 } & $\leq 40$ & 46 & 46 \\
\hline \multirow{3}{*}{ Age (years) } & $>40$ & 54 & 54 \\
\hline & Min. - Max. & $18.0-61.0$ \\
\cline { 2 - 4 } & Mean \pm SD. & $41.74 \pm 10.77$ \\
\hline & Median & \multicolumn{2}{|c|}{41.5} \\
\hline
\end{tabular}


Table (2): Descriptive analysis of the studied cases according to height, weight, BMI, heart rate and blood pressure $(\mathbf{n}=\mathbf{1 0 0})$

\begin{tabular}{||l|c|l|l|}
\hline & Min. - Max. & Mean \pm SD. & Median \\
\hline Height $(\mathbf{c m})$ & $159.0-190.0$ & $170.9 \pm 7.13$ & 170.0 \\
\hline Weight $(\mathbf{k g})$ & $69.0-115.0$ & $86.36 \pm 9.11$ & 86.0 \\
\hline BMI $\left(\mathbf{k g} / \mathbf{m}^{\mathbf{2}}\right)$ & $23.30-35.50$ & $29.55 \pm 2.55$ & 29.50 \\
\hline Heart Rate & $52.0-105.0$ & $76.45 \pm 10.07$ & 76.0 \\
\hline Systolic & $100.0-139.0$ & $119.6 \pm 10.38$ & 120.0 \\
\hline Diastolic & $70.0-89.0$ & $77.08 \pm 6.35$ & 78.0 \\
\hline
\end{tabular}

Table (3): Distribution of the studied cases according to normality of blood analysis and chest $X$ ray $(n=100)$

\begin{tabular}{||l|l|c||}
\hline & No. & \% \\
\hline Blood glucose / HA1C & 100 & 100.0 \\
\hline Lipid profile & 100 & 100.0 \\
\hline Chest X ray & 100 & 100.0 \\
\hline
\end{tabular}

Table (4): Descriptive analysis of the studied cases according to different echo parameters $(n=100)$

\begin{tabular}{|l|c|c|c|}
\hline \multicolumn{1}{|c|}{ Echo } & Min. - Max. & Mean \pm SD. & Median \\
\hline LV Mass (gm) & $120.0-440.0$ & $194.4 \pm 73.39$ & 166.9 \\
\hline LVIDD (mm) & $34.0-59.0$ & $47.24 \pm 6.0$ & 46 \\
\hline EAA (mlsec) & $0.61-2.20$ & $1.01 \pm 0.31$ & 1 \\
\hline $\begin{array}{l}\text { Estimated } \\
\text { PASP (mmHg) }\end{array}$ & $15.0-44.0$ & $\begin{array}{c}24.22 \pm \\
5.84\end{array}$ & 23 \\
\hline L.A. volume Ele & $4.67-17.70$ & $8.53 \pm 2.50$ & 8.12 \\
\hline
\end{tabular}

In present study age, sex and smoking were significantly different between the two major groups (normal blood pressure and latent hypertension, table 6).

On comparing the two groups according the circadian rhythm there was significant difference only in ambulatory results (Tables 5-6).

Table (5): Comparison between normal and latent groups according to ambulatory result $(n=100)$

\begin{tabular}{|c|c|c|c|c|c|c|c|}
\hline & & \multirow{2}{*}{\multicolumn{4}{|c|}{ Ambulatory result }} & & \multirow{4}{*}{$\mathbf{p}$} \\
\hline & & & & & & \multirow{3}{*}{$\begin{array}{c}\text { Test of } \\
\text { Sig. }\end{array}$} & \\
\hline & & \multicolumn{2}{|c|}{ Normal $(\mathbf{n}=$} & \multicolumn{2}{|c|}{$=46) \quad$ Latent (n } & & \\
\hline & & No. & $\%$ & No. & $\%$ & & \\
\hline \multirow{2}{*}{ Gender } & Male & 26 & 48.1 & 40 & 87 & \multirow{2}{*}{$\begin{array}{c}\chi 2= \\
16.672 *\end{array}$} & \multirow{2}{*}{$<0.001^{*}$} \\
\hline & Female & 28 & 51.9 & 6 & 13 & & \\
\hline \multirow{3}{*}{ Age } & Min. - Max. & \multirow{2}{*}{\multicolumn{2}{|c|}{$\begin{array}{r}18.0-61.0 \\
3841+1151\end{array}$}} & \multicolumn{2}{|c|}{$32.0-58.0$} & \multirow{3}{*}{$\mathrm{t}=3.633^{*}$} & \multirow{3}{*}{$<0.001 *$} \\
\hline & Mean \pm SD & & & \multicolumn{2}{|c|}{$45.65 \pm 8.37$} & & \\
\hline & Median & \multicolumn{2}{|c|}{$\frac{38.41 \pm 11.51}{37}$} & & 45 & & \\
\hline \multirow{2}{*}{ Smoking } & Non smoker & 42 & 77.8 & 20 & 43.5 & \multirow{2}{*}{$\begin{array}{c}\chi 2= \\
12.404 *\end{array}$} & \multirow{2}{*}{$<0.001 *$} \\
\hline & Smoker & 12 & 22.2 & 26 & 56.5 & & \\
\hline \multirow{4}{*}{$\begin{array}{c}\text { Diastolic } \\
\text { Dysfunction }\end{array}$} & Absent & 32 & 59.3 & 23 & 50 & \multirow{2}{*}{$\begin{array}{r}\chi^{2}= \\
0.860\end{array}$} & \multirow{2}{*}{0.354} \\
\hline & Present & 22 & 40.7 & 23 & $\mathbf{5 0}$ & & \\
\hline & Grade I & 16 & 72.7 & 13 & 56.5 & \multirow{2}{*}{$\begin{array}{r}\chi^{2}= \\
1.289\end{array}$} & \multirow{2}{*}{0.256} \\
\hline & Grade II & 6 & 27.3 & 10 & 43.5 & & \\
\hline \multirow{3}{*}{ LV Mass (gm) } & Min. - Max. & \multicolumn{2}{|c|}{$121.4-362.9$} & \multicolumn{2}{|c|}{$120.0-440.0$} & \multirow{3}{*}{$\mathrm{U}=1182.0$} & \multirow{3}{*}{0.678} \\
\hline & Mean \pm SD & \multirow{2}{*}{\multicolumn{2}{|c|}{$\begin{array}{r}191.7 \pm 64.09 \\
172.2\end{array}$}} & \multirow{2}{*}{\multicolumn{2}{|c|}{$\begin{array}{r}197.5 \pm 83.62 \\
164.8\end{array}$}} & & \\
\hline & Median & & & & & & \\
\hline \multirow{2}{*}{$\begin{array}{l}\text { Circadian } \\
\text { rhythm }\end{array}$} & Normal & 34 & 63 & 15 & 32.6 & \multirow[b]{2}{*}{$\chi 2=9.159^{*}$} & \multirow[b]{2}{*}{$<0.003 *$} \\
\hline & $\begin{array}{c}\text { Impaired } \\
\text { circadian rhythm }\end{array}$ & 20 & 37 & 31 & 67.4 & & \\
\hline
\end{tabular}


Table (6): Comparison between normal and impaired circadian groups $(n=100)$

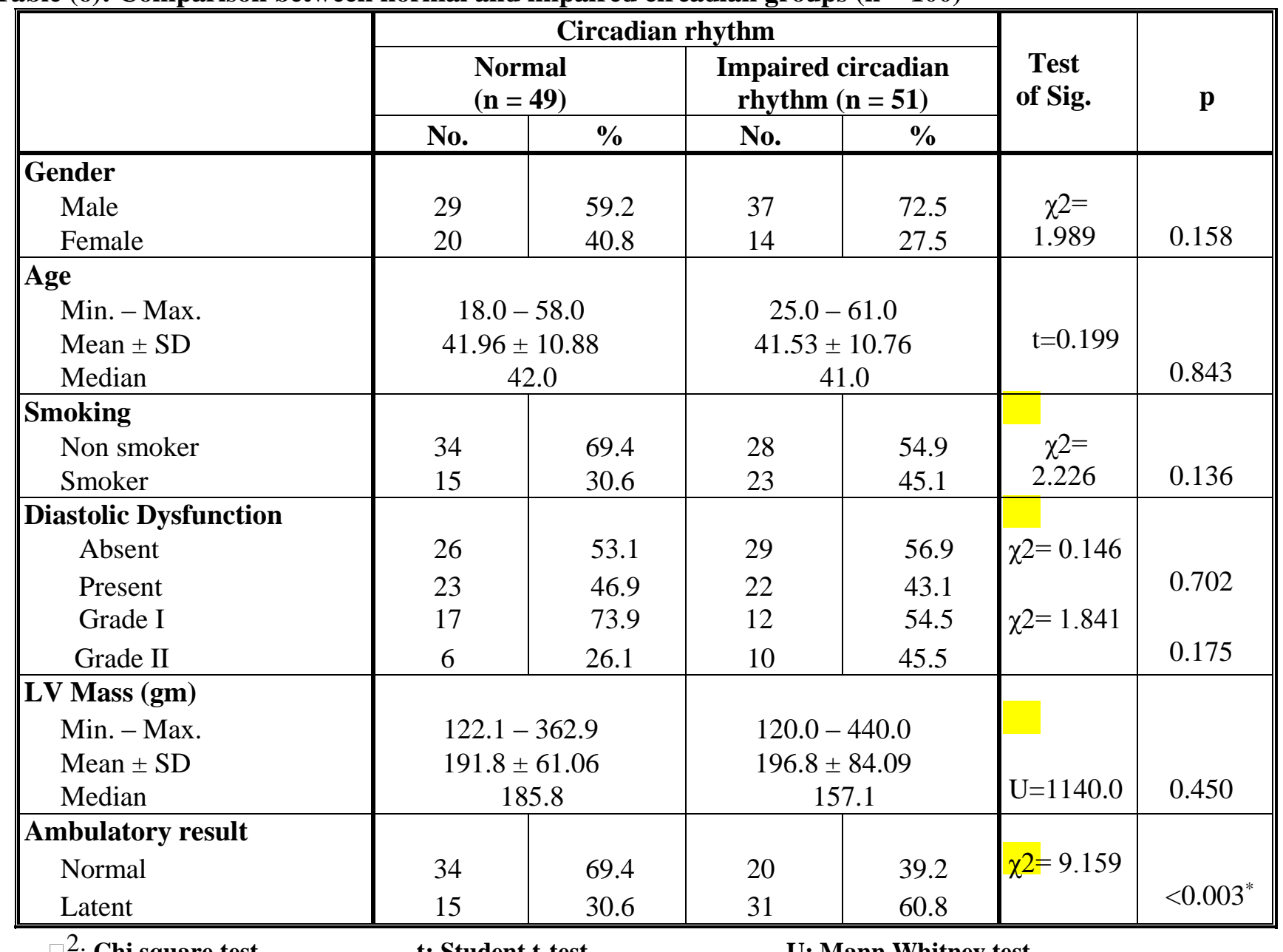

$7^{2}$ : Chi square test

\section{DISCUSSION}

Hypertension (HTN), is a long term medical condition in which the blood pressure in the arteries is persistently elevated ${ }^{(7)}$. Long term high blood pressure, however, is a major risk factor for coronary artery disease, stroke, heart failure, peripheral vascular disease, vision loss and chronic kidney disease ${ }^{(8)}$.

We worked in this study to assess the prevalence of blood pressure variability in patients with diastolic dysfunction and increased left ventricular mass. We also aimed to clarify ambulatory predictors and to estimate prevalence of hypertension based on diastolic dysfunction and increased left ventricular mass.

Our study groups were classified as;

According to the level of ambulatory BP result into: those had normal blood pressure (54\%) and those had latent hypertension (46\%).

According to the circadian rhythm into those had normal circadian rhythm (49\%) and those had impaired circadian rhythm (51\%).

Our results were in agreement with Feola $\boldsymbol{e t}$ al. ${ }^{(9)}$. They studied 52 subjects and the clinical history showed at least one BP measurement > $140 / 90 \mathrm{mmHg}$ in the year prior to observation. The average age was $48+11$, without any significant correlation to LVMI $(\mathrm{r}=0.13)$. Their results showed LVMI had a significant correlation with systolic BP at ABPM (24 h systolic BP $r=0.34$; daytime systolic $\mathrm{BP} \mathrm{r}=0.35$; nighttime systolic $\mathrm{BP}$ $r=0.28 ; 6-12$ systolic BP $r=0.29$ ) but not with diastolic BP.

This was not matching with current study in diastolic BP. This discrepancy between results is partly attributed to the large number of current study ethnical, regional, lifestyle pattern differences and difference of subset inclusion criteria. Dipper patients represented $76.3 \%$ of the population, without any difference in LVMI between dippers and non-dippers $(p=0.09)$. Dipper patients had a higher prevalence of normal left ventricles as compared with non-dippers ( $\mathrm{p}<$ 0.0001).

Our study also was in agreement with Ito et al. ${ }^{(10)}$. They studied 36 untreated hypertensive nondiabetic patients (16 males and 20 females) whose casual systolic blood pressure (CSBP) and/or diastolic blood pressure (CDBP) were higher than $140 \mathrm{mmHg}$ and $90 \mathrm{mmHg}$, respectively. All patients were less than 65 years of age without organic heart disease. Their results showed 
significant positive correlations between the LVMI and ASBP $(r=0.51, p<0.005)$, the SHI $(r=0.49$, $\mathrm{p}<0.005)$, CSBP $(r=0.47, \mathrm{p}<0.01)$ and RSBP $(r$ $=0.41, \mathrm{p}<0.05)$, however, there were no significant correlations between the LVMI and ADBP. This was not matching with current study in ADBP. This discrepancy between results is partly attributed to the large number of current study ethnical, regional, lifestyle pattern differences and difference of subset inclusion criteria.

Our results were also in agreement with Müller-Brunotte et al. ${ }^{(11)}$. Their results showed that hypertension is associated with LV diastolic dysfunction, and diastolic function is further impaired in the presence of hypertensive LV hypertrophy. Indeed, LV diastolic dysfunction is considered to be an early sign of hypertensive heart disease.

According to (normal circadian and impaired circadian) there was insignificant difference between the two major groups in sex where male $>$ female $(\mathrm{p}$ value $=0.158)$ and LV mass where $(\mathrm{p}$ value, <0.450) and smoking (p-value, <0.136). There was significant difference in ambulatory result (p-value, <0.003) that was in agreement with Verdecchia et al. (12) except in gender where female in this study >male. This discrepancy between results is partly attributed to ethnical, regional, lifestyle pattern differences.

\section{CONCLUSION}

Hypertension determines an increased risk of cardiovascular events which may be predicted by the occurrence of target-organ damage (TOD). In addition to elevated mean levels of blood pressure (BP), short- term daytime or 24-h BP variability (BPV) has been shown to carry an independent prognostic value in hypertensive patients and is directly related to TOD. Whenever present, left ventricular diastolic dysfunction in hypertension, even if asymptomatic, is a potent predictor of adverse cardiovascular events. Ambulatory blood pressure (AMBP) plays an important role as a predictor to estimate prevalence of hypertension based on diastolic dysfunction and increased left ventricular mass in persons with normal blood pressure measures at office specially masked hypertension in white coat hypertensive patients.

\section{RECOMMENDATION}

1. Multiple cardiology centers sharing in large study.

2. Including patients with renal dysfunction (serum creatinine $\geq 2 \mathrm{mg} / \mathrm{dl}$ or macro albuminuria $\geq 300 \mathrm{mg} / 24 \mathrm{~h}$.

3. Including diabetic patients.

4. Survey of all family members who were diagnosed as hypertensive patient.

\section{REFERENCES}

1. Cuspidi C, Lonati L, Sampieri L et al. (2000): Prevalence of target organ damage in treated hypertensive patients: different impact of clinic and ambulatory blood pressure control. J Hypertens., 18:803-809.

2. Parati G, Stergiou GS, Asmar R et al. (2008): European Society of Hypertension guidelines for blood pressure monitoring at home: a summary report of the Second International Consensus Conference on Home Blood Pressure Monitoring. J Hypertens., 26:15051526.

3. Verdecchia $P$, Angeli $F$, Gattobigio $R$ et al. (2005): Asymptomatic left ventricular systolic dysfunction in essential hypertension: prevalence, determinants, and prognostic value. Hypertension, 45(3):412-8.

4. Parati G, Onchoa JE and Lombardi C (2013): Assessment and management of blood pressure variability. Nat Rev Cardiol., 10; 143-155.

5. Owens P, Atkins N and O'Brien E (1999): Diagnosis of white coat hypertension by ambulatory blood pressure monitoring. Hypertension, 34:267-72.

6. Mancia G, De Backer G, Dominiczak A et al. (2007): ESH-ESC Practice Guidelines for the Management of Arterial Hypertension: ESH- ESC Task Force on the Management of Arterial Hypertension. J. Hypertens., 25 (9): 1751-62.

7. Naish J, Court D S (2014): Medical sciences (2 ed.); p. 562 ISBN 9780702052491. https://www.elsevier.com/books/medicalsciences/naish/978-0-7020-5138-8

8. Lackland DT, Weber MA (2015): Global burden of cardiovascular disease and stroke: hypertension at the core. The Canadian Journal of Cardiology, 31 (5): 56971.

9. Feola M, Boffano GM, Procopio M et al. (1998): Ambulatory 24-hour blood pressure monitoring: correlation between blood pressure variability and left ventricular hypertrophy in untreated hypertensive patients. G Ital Cardiol., 28(1):38-44.

10.Ito O, Okamoto M, Murakami Y et al. (1991): Correlations between blood pressure, left ventricular hypertrophy, and left ventricular diastolic function in hypertensive patients]. J Cardiol., 21(4):931-41.

11. Müller-Brunotte R, Kahan T, López B et al. (2007): Myocardial fibrosis and diastolic dysfunction in patients with hypertension: results from the Swedish Irbesartan Left Ventricular Hypertrophy Investigation versus Atenolol (SILVHIA). J Hypertens., 25(9):195866.

12. Verdecchia P, Palatini P, Schillaci G et al. (2001): Independent predictors of isolated clinic ("whitecoat') hypertension. J Hypertens., 19:1015-20. 